\title{
Effect of Acute Hepatitis E Infection in Patients with Liver Cirrhosis
}

\author{
KC S, ${ }^{1}$ Sharma D, ${ }^{2}$ Basnet BK, ${ }^{1}$ Mishra AK' \\ 'Liver unit Bir Hospital, National Academy of Medical Sciences, ${ }^{2}$ Medicine Unit Bir Hospital, National Academy of Medical \\ Sciences, Kathmandu, Nepal.
}

\section{ABSTRACT}

Introduction: Hepatitis E virus is a major cause of enterically transmitted hepatitis. Mortality is very high if it is associated with pregnancy, especially during third trimester. This study was carried out to find out the effects of acute HEV hepatitis on Chronic Liver Disease patients of different etiologies.

Methods: The consecutive patients of liver cirrhosis with definite evidence of recent HEV infection were enrolled in this study. Acute hepatitis was diagnosed by presence of prodromal symptoms and anti-HEV IgM antibody in their serum. The outcomes after superinfection with HEV hepatitis were determined by changes in Child Pugh score, recovery of liver function test, hospital stay and mortality.

Results: After exclusion 25 were studied. The etiology of cirrhosis in patients was: alcohol 13, autoimmune hepatitis 3, hepatitis B 2, Budd Chiari syndrome 2, alcohol plus hepatitis B 1, hepatitis C 1 , cardiac cirrhosis 1 , Wilson's disease 1 and cryptogenic 1 . All patients with no recent decompensation showed signs of decompensation during admission. Seven $(28 \%)$ patients died. The cause of death was either upper gastrointestinal bleeding or hepatorenal syndrome. Remaining patients had prolonged hospital stay with deterioration of Child-Pugh's score.

Conclusions: Superinfection of HEV in cirrhotic patient causes rapid decompensation. The morbidity and mortality is higher compared to those non-infected patients. Development of hepatorenal syndrome and upper GI bleeding was commonest cause of death.

Key Words: acute HEV infection, Chronic liver disease, third trimester pregnancy

\section{INTRODUCTION}

Hepatitis E virus (HEV) is a major cause of enterically transmitted hepatitis worldwide. ${ }^{1,2,3}$ In Kathmandu, an epidemic of viral hepatitis was reported in 1973, associated with high mortality rate in pregnant women. ${ }^{4}$ Clinical features of HEV include fever, jaundice, dark urine, anorexia, nausea, vomiting, abdominal pain, myalgia, and arthralgia., ${ }^{1,5-8}$ About $5 \%$ of patients also present with anicteric hepatitis and marked cholestasis. $^{9,10}$ Mortality is very high if it is associated with pregnancy, especially during third trimester. ${ }^{4,7,8}$ Hepatitis B, Hepatitis D and Hepatitis A virus can induce liver injury and de-compensation among patients with chronic liver disease (CLD), however data on role of $\mathrm{HEV}$ infection in worsening of pre-existing CLD

Correspondence:

Dr. Sudhamshu KC

Liver Unit, Bir Hospital

National Academy of Medical Sciences

Kathmandu, Nepal.

Email: sudhamshu.liver@gmail.com

Phone: 977-1-4215709, 
KC et al. Effect of Acute Hepatitis E Infection in Patients with Liver Cirrhosis

are limited. ${ }^{12,13}$ Natural history of superimposed HEV infection in CLD is highlighted in that more than $80 \%$ patients of CLD are prone to this infection in endemic areas. ${ }^{11}$ This study aims to find out the effects of acute HEV hepatitis on CLD patients.

\section{METHODS}

A prospective observational study was carried in Bir hospital and Norvic hospital in Kathmandu, Nepal from December 2004 to December 2005. Ethical approval and written consent was taken. Thirty-four consecutive patients of CLD were enrolled in the study. Nine patients were excluded due to presence of hepatocellular carcinoma $(n=1)$, septicemia $(n=2)$ uncontrolled DM $(n=2)$, and recent history of bleeding $(n=4)$. Twentyfive patients of previously diagnosed liver cirrhosis, who were in regular follow up in either hospital with definite evidence of recent HEV infection were enrolled in this study. They were hospitalized for close observation and better management. Liver cirrhosis was diagnosed on the basis of history, clinical examination, laboratory parameters, imaging diagnosis and/or histopathological examinations. Acute HEV hepatitis was diagnosed by prodromal symptoms and confirmed by presence of anti HEV IgM in the serum by ELISA. Superinfection from other viruses such as hepatitis $B$ and hepatitis $C$ were excluded by testing $\mathrm{HBsAg}$, anti $\mathrm{HBc} \operatorname{lgM}$ and anti $\mathrm{HCV}$ in the serum. Ultrasound examination was repeated in every patient at the time of presentation with special focus on space occupying lesion and portal vein thrombosis. CT examination was done only when indicated. Peritoneal fluid analysis including culture sensitivity test was done in patients presenting with ascites at the time of presentation. Complete blood count, liver function tests, liver biochemistry, alfa feto protein and blood culture sensitivity tests, ECG and chest x-ray were carried in all patients. Special tests like echocardiography, endoscopy etc were done whenever required. The main outcomes were determined by changes in Child Pugh score, recovery time for liver function test, hospital stay and mortality. Recovery of liver function test was defined as return of parameters of liver function test and Child Pugh score to baseline level. The patients were discharged if they were hemodynamically stable and Child Pugh score returned to or reached near to pre admission level (regression of ascites, fall in bilirubin level, decrease in prothrombin time, reversal of hepatic encephalopathy. SPSS 10.0 version was used for statistical analysis.

\section{RESULTS}

Mean age of the patient at the time of presentation was 41.8(14-68) years. Ageand sex distribution of the patients are given in table 1 . There was male preponderance with a M:F ratio of $1.7: 1$. Prodromal symptoms were present in $56 \%$ of the patients. Three presented with intense pruritus causing sleep loss. Obstructive jaundice was ruled out by ultrasound examination. Total serum bilirubin at the time of presentation was 2.6-35 mg/dL. Mean serum alanine transaminase (ALT) and aspartate transaminase (AST) were 580 (215-2065) and 378 (119-3078) IU/L respectively. The mean ALT/AST values before superinfection with $\mathrm{HEV}$ was $48 / 74$ (ref range 35/50). It was little higher for patients of alcoholic LC 58/84. Serum albumin was between 2.2$3.8 \mathrm{gm} \%$. Prothrombin time was prolonged in all but three patients ranging from 15 to 39 seconds. Control was 12 seconds. Ascites was present in $80 \%$ (20/25) of the patient. Seven patients presented with hepatic encephalopathy of grade I to III. Spontaneous bacterial peritonitis was diagnosed in $70 \%(14 / 20)$ on the basis of polymorphonuclear leucocytosis in ascitic fluid. Organism was identified in three patients and it was E. coli in all rhree subjects. Etiology of CLD is given in table 2. All patients were in Child $A$ as graded by Child Pugh scoring before superinfection with HEV. Majority of the patients (68\%) had grade II-III esophageal varices before admission. Seven patients had undergone prophylactic variceal banding. At the time of presentation four

Table 1. Age and sex distribution of the patients

\begin{tabular}{lll}
\hline Etiology & Sex (M/F) & Age (mean) \\
\hline Alcohol & $9 / 4$ & $38-68$ (44 years) \\
Autoimmune hepatitis & $0 / 3$ & $48-56$ (50 years) \\
Budd Chiari syndrome & $1 / 1$ & $22-40$ (31 years) \\
$\begin{array}{ll}\text { Hepatitis B } \\
\text { Alcohol plus hepatitis B }\end{array}$ & $1 / 0$ & 38 years \\
$\begin{array}{l}\text { Hepatitis C (plus } \\
\text { alcohol) }\end{array}$ & $1 / 0$ & 35 years \\
$\begin{array}{l}\text { Wilson's disease } \\
\text { Cardiac cirrhosis }\end{array}$ & $1 / 0$ & 14 years \\
$\begin{array}{l}\text { Cryptogenic liver } \\
\text { cirrhosis (? NASH) }\end{array}$ & $0 / 1$ & 54 years \\
\hline
\end{tabular}

Table 2. Etiologies of chronic liver disease in study population

\begin{tabular}{lc}
\hline Etiology & No. of patients (\%) \\
\hline Alcohol & $13(52)$ \\
Autoimmune hepatitis & $3(12)$ \\
Budd chiari syndrome & $2(8)$ \\
Hepatitis B & $2(8)$ \\
Alcohol plus hepatitis B & $1(4)$ \\
Hepatitis C (plus alcohol) & $1(4)$ \\
Wilson's disease & $1(4)$ \\
Cardiac cirrhosis & $1(4)$ \\
Cryptogenic liver cirrhosis & $1(4)$ \\
(? NASH) & \\
\hline
\end{tabular}


KC et al. Effect of Acute Hepatitis E Infection in Patients with Liver Cirrhosis

Table 3. Outcomes of study population after superinfection with HEV hepatitis.

\begin{tabular}{|c|c|c|c|c|}
\hline \multirow[b]{2}{*}{ Case no. } & \multicolumn{2}{|c|}{ Child-Pugh score } & \multirow{2}{*}{$\begin{array}{l}\text { Recovery } \\
\text { time for } \\
\text { LFT in days }\end{array}$} & \multirow{2}{*}{$\begin{array}{l}\text { Hospital } \\
\text { stay in } \\
\text { days }\end{array}$} \\
\hline & $\begin{array}{c}\text { before } \\
\text { infection }\end{array}$ & $\begin{array}{c}\text { at } \\
\text { admission }\end{array}$ & & \\
\hline 1 & 6 & 15 & - & $27 *$ \\
\hline 2 & 6 & 10 & 68 & 16 \\
\hline 3 & 5 & 8 & 60 & 20 \\
\hline 4 & 6 & 15 & 45 & 33 \\
\hline 5 & 6 & 8 & 32 & 7 \\
\hline 6 & 6 & 12 & 45 & 12 \\
\hline 7 & 5 & 6 & 30 & 5 \\
\hline 8 & 6 & 10 & 40 & 15 \\
\hline 9 & 6 & 15 & - & $8^{*}$ \\
\hline 10 & 5 & 6 & 35 & 6 \\
\hline 11 & 6 & 8 & 41 & 18 \\
\hline 12 & 6 & 13 & 58 & $35 * *$ \\
\hline 13 & 6 & 10 & 36 & 20 \\
\hline 14 & 6 & 12 & 55 & 17 \\
\hline 15 & 5 & 7 & 46 & 12 \\
\hline 16 & 6 & 9 & 44 & 10 \\
\hline 17 & 6 & 15 & - & $5 * * *$ \\
\hline 18 & 5 & 14 & - & $12^{*}$ \\
\hline 19 & 5 & 7 & 50 & 8 \\
\hline 20 & 6 & 10 & 45 & 16 \\
\hline 21 & 6 & 9 & 52 & 10 \\
\hline 22 & 6 & 15 & 75 & $33^{* *}$ \\
\hline 23 & 5 & 9 & 35 & 8 \\
\hline 24 & 5 & 9 & 55 & 12 \\
\hline 25 & 5 & 15 & 36 & $22 * *$ \\
\hline
\end{tabular}

* Patient died during admission, ** Patients died during readmission, *** Patient died waiting for liver transplantation

Table 4. Etiology of the patient with mortality

\begin{tabular}{lll}
\hline Timing of death & Etiology & No. \\
\hline $\begin{array}{l}\text { Death during initial } \\
\text { hospital stay }\end{array}$ & Alcohol & 2 \\
Cardiac cirrhosis & 1 \\
$\begin{array}{l}\text { admission } \\
\text { Death during re- }\end{array}$ & Alcohol & 2 \\
for transplantation & Hepatitis C (plus alcohol) & 1 \\
\hline
\end{tabular}

were $A$, seven were $B$ and remaining 14 patients were C. Outcome of the patients are given in table 3 .
Mortality rate was high, $28 \%$ in total. Three patients died within hospital stay and the cause of death was hepatorenal syndrome in two patients and massive upper gastrointestinal bleeding in one patient. Three patients died during readmission. Cause of death was hepatorenal syndrome in two and upper gastrointestinal bleeding with complications of shock in one. One patient died waiting for transplantation. Etiologies of LC of the patients who died are given in table 4 . Recovery time for LFT was very much prolonged compared to nonCLD patients ranging from 30-75 days. Hospital stay was also longer compared to other CLD patients who were taken as classical control.

\section{DISCUSSION}

This study shows that rapid decompensation of CLD is associated after superinfection with acute HEV hepatitis. Hamid et al were first to report HEV superinfection as a cause of decompensation in CLD patients. ${ }^{11}$ They reported four patients with stable disease who developed severe liver decompensation and were found to have serological evidence of HEV infection; one of these patients died whereas three improved. In this study commonest sign of decompensation was rapid development of jaundice and ascites. Ascitic fluid was frequently infected giving rise to spontaneous bacterial peritonitis. Mortality rate was also high reaching $28 \%$. Renal failure and massive GI bleeding were the causes of mortality. Comparable results were obtained in the study by Monga et al. ${ }^{14}$ Morbidity in terms of longer hospital stay and long recovery time for LFT was high. Study by Kumar et al $^{15}$ showed similar findings. Though mortality was less, there was definite decompensation of CLD after superinfection with HEV compared to other CLD patient without HEV infection. Several studies have showed that there is poor outcome in CLD patients after HEV superinfection. However, the exact mechanism is still unclear. Rapid destruction of hepatocyte due to HEV infection may be plausible explanation for the rapid deterioration. The prevalence of IgG anti-HEV antibodies among the adult population in endemic regions is only $33 \%-40 \% .{ }^{16}$ In another study by Hamid et al, they have shown that more than $80 \%$ of (CLD) patients lack these antibodies. ${ }^{11}$ This may predispose them to severe liver decompensation when there is superimposed HEV infection in already decreased hepatic reserve. Why it is fatal in some and not in others is still a matter to be searched.

This study has some limitations. Though this study suggests a role for HEV infection in decompensation of liver cirrhosis, it does not provide an estimate of true frequency of such occurrence. Other factors that may be responsible for decompensation, as for example, ingestion of herbal medications of unknown nature, diet restriction (after observing jaundice) as 
practiced in third world countries were not considered for investigations. Serology for hepatitis D was not done in patients with hepatitis B patients. This study has a potential implication regarding management of CLD in an endemic region. Hepatitis $E$ infection in this setting has a protracted course with high morbidity and mortality. Preliminary report on HEV vaccination has been published. ${ }^{17}$ If it is established CLD patients of endemic region or CLD patients going to endemic zone should receive vaccination against $\mathrm{HEV}$. In the meantime, such patients should take proper measures to avoid contaminated food and beverages.

\section{CONCLUSIONS}

This study shows that superinfection of HEV in cirrhotic patient causes rapid decompensation. The morbidity and mortality is higher compared to those non-infected patients. Development of hepatorenal syndrome and upper GI bleeding was commonest cause of death.

\section{REFERENCES}

1. Aggarwal A, Krawczynski K. Hepatitis E: an overview and recent advances in clinical and laboratory research. J Gastro Hepatol. 2000;15:9-20.

2. Harrison TJ. Hepatitis E virus-an update. Liver. 1999;19:171-6.

3. Naidu SS, Viswanathan R. Infectious hepatitis in pregnancy during Delhi epidemic. Ind J Med Res. 1957;45:1-30.

4. Kane MA, Bradley DW, Shrestha SM, Maynard JE, Cook EH, Mishra RP et al. Epidemic non-A, non-B hepatitis in Nepal. Recovery of a possible etiologic agent and transmission studies in marmosets. JAMA. 1984 Dec 14;252(22):3140-5.

5. Khuroo MS, Rustgi VK, Dawson GJ, Mushahwar IK, Yattoo GN, Kamili S et al. Spectrum of hepatitis E virus infection in India. J Med Virol. 1994 Jul;43(3):281-6.

6. Kaur R, Gur R, Berry N, Kar P. Etiology of endemic viral hepatitis in urban North India. Southeast Asian J Trop Med Public Hlth 2002;33:845-8.

7. Purcell RH, Emerson SU. Hepatitis E Virus. In: Mandell GL, Bennett JE, Dolin R, ed. Principles and practice of infectious diseases. Philadelphia: Churchill Livingstone; 2000. p. 1958-70.

8. Yarbough PO. Hepatitis E virus: diagnosis. In: Zuckerman AJ, Thomas HC, ed. Viral hepatitis. London: Churchill Livingstone; 1998. p.411-6.

9. KCS. Ultrasound findings in acute viral hepatitis. Kathmandu Univ Med J (KUMJ). 2006 Oct- Dec;4(4):415-8.
10. Zhuang H, Cao X, Liu C, Wang G. Enterically transmitted non-A, non-B hepatitis in China. In: Shikata T, Purcell RH, Uchida T, Eds. Viral hepatitis C, D and E. Amsterdam: Excerpta Medica; 1991. p.277-85.

11. Hamid SS, Atiq M, Shehzad F, Yasmeen A, Nissa T, Salam A et al. Hepatitis $\mathrm{E}$ virus superinfection in patients with chronic liver disease. Hepatology. 2002 Aug;36(2):474-8.

12. Vento S, Garofano T, Renzine C, Cainelli F, Casali F, Ghironzi $\mathrm{G}$, et al. Fulminant hepatitis associated with hepatitis A virus superinfection in patients with chronic hepatitis C. N Engl J Med. 1998;338:286-90.

13. Krawczynski K, Aggarwal R. Hepatitis E. In: Schiff ER, Sorell MF, Maddrey WC Eds. Schiff's Diseases of the Liver. Philadelphia: Lippincott-Williams \& Wilkins; 2002. p.877-90.

14. Kumar A, Aggarwal R, Naik SR, Saraswat V, Ghoshal UC, Naik S. Hepatitis E virus is responsible for decompensation of chronic liver disease in an endemic region. Indian J Gastroenterol. 2004 Mar-Apr;23(2):59-62.

15. Monga R, Garg S, Tyagi P, Kumar N. Superimposed acute hepatitis $\mathrm{E}$ infection in patients with chronic liver disease. Indian J Gastroenterol. 2004 Mar-Apr; 23(2):50-2.

16. Arankalle VA, Tsarev SA, Chadha MS, Alling DW, Emerson SU, Banerjee K, et al. Age-specific prevalence of antibodies to hepatitis A and E viruses in Pune, India, 1982 and 1992. J Infect Dis. 1995 Feb;171(2):447-50.

17. Shrestha MP, Scott RM, Joshi DM, et al. Safety and efficacy of a recombinant hepatitis $\mathrm{E}$ vaccine. $\mathrm{N}$ Engl J Med. 2007;356:895-903. 